\title{
Eventos extremos hidroclimáticos e percepção da dinâmica sociocultural por ribeirinhos da Amazônia
}

\author{
Extreme hydroclimatic events and perception of sociocultural dynamics by Amazon riverside \\ communities
}

Eventos hidroclimáticos extremos y percepción de la dinámica sociocultural por ribereños de la Amazonía

Recebido: 15/06/2021 | Revisado: 21/06/2021 | Aceito: 25/06/2021 | Publicado: 11/07/2021

Mônica Alves de Vasconcelos
ORCID: https://orcid.org/0000-0003-0388-5791
Universidade Federal do Amazonas, Brasil
E-mail: monica.engbio@gmail.com
David Franklin da Silva Guimarães
ORCID: https://orcid.org/0000-0002-4569-6000
Universidade Federal do Amazonas, Brasil
E-mail: davidguimaraes2009@hotmail.com
Henrique dos Santos Pereira
ORCID: https://orcid.org/0000-0002-9113-1166
Universidade Federal do Amazonas, Brasil
E-mail: hpereira @ufam.edu.br
José Cavalcante Lacerda Júnior
ORCID: https://orcid.org/0000-0001-9697-8377
E-mail: psi.josecavalcante@gmail.com
Myriam Lopes
Instituto Federal de Educação, Ciência e Tecnologia do Amazos, Brasil
ORCID: https://orcid.org/0000-0002-7624-1279
Universidade de Aveiro, Portugal
E-mail: myr@ ua.pt

\section{Resumo}

O presente trabalho teve como objetivo verificar a percepção de comunitários ribeirinhos da Reserva de Desenvolvimento Sustentável do Rio Negro sobre as mudanças na dinâmica paisagística provocada por eventos extremos hidroclimáticos. Foram realizadas oficinas de mapas mentais em quatro comunidades da reserva, sendo elas Tiririca, Santo Antônio e Marajá no município de Novo Airão e Terra Preta em Iranduba. Participaram do estudo 50 comunitários divididos em grupos focais de homens e mulheres. Ambos os grupos foram orientados a elaborar o mapa mental da comunidade que ilustrassem dois momentos: uma grande cheia e uma grande seca do rio Negro, observando a diferença de percepção entre os gêneros diante dos eventos extremos. Ao final, cada grupo expôs o detalhamento dos mapas elaborados a todos os participantes e organizadores. As respostas indicam dois grupos principais de destaque na percepção dos ribeirinhos: os elementos naturais e culturais da paisagem. Entre os naturais destacam-se a dinâmica das águas e a quentura, e como culturais a escada e a igreja. De todos os elementos citados, a quentura teve maior destaque, tanto nos grupos de homens quanto no das mulheres de todas as comunidades trabalhadas. Os mapas e as narrativas apontam diferenças sutis nas percepções entre os grupos e estes sentem maiores impactos negativos com as secas extremas. Os comunitários percebem as mudanças em relação aos eventos fluviais e pluviais, e do aumento da sensação térmica por meio da quentura.

Palavras-chave: Mapas mentais; Grupos focais; Percepção climática na Amazônia; Comunidades da Amazônia.

\begin{abstract}
The present work aims to verify the perception of members of riverside communities in the Sustainable Reserve of Rio Negro, Amazonas, on changes in landscape dynamics generated by extreme hydroclimatic events. Workshops of mind maps will be held in four communities of the reserve, which are: Tiririca, Santo Antonio and Marajá, in the municipality of Novo Airão and Terra Preta in the municipality of Iranduba. Fivety community members participated, divided into focus groups of men and women. Both groups were oriented to draw up a mental map in which ilustrate: A long period of drought and a long period of avenue in Rio Negro. It was observed that it differentiates in the perception between the genres about these extreme events. Finally, each group displayed in detail the maps made to all participants and organizers of the workshop. Among the answers, two groups stand out in the perception of the riverside people: natural and cultural elements of the landscape. In the natural elements, the dynamics of the waters and the heat, among the cultural ones, the ladders and the Church. Of all the elements mentioned, the heat is the most
\end{abstract}


prominent, both in the groups of men and women in all the communities worked on. The maps and the narratives point out subtle differences in the perceptions between the groups, the same ones, having greater negative impacts in the extreme droughts. Community members perceive changes in relation to river and rain events, and temperature increase through heat.

Keywords: Mind maps; Focus groups; Climate perception in the Amazon; Communities in the Amazon.

\section{Resumen}

El presente trabajo tubo como objetivo verificar la percepción de miembros de comunidades ribereñas de la Reserva Sustentable del Río Negro, Amazonas, sobre los cambios en la dinámica paisajística generada por eventos hidroclimáticos extremos. Se realizaron talleres de mapas mentales en cuatro comunidades de la reserva las cuales fueron: Tiririca, Santo Antonio y Marajá, en el municipio de Novo Airão y Terra Preta en el municipio de Iranduba. Participaron 50 miembros comunitários divididos en grupos focales de hombres y mujeres. Ambos grupos fueron orientados a elaborar un mapa mental en el cual se ilustren dos momentos: Un gran período de estiaje y un gran período de avenida en el Río Negro. Se observó la diferencia en la percepción entre los géneros sobre estos eventos extremos. Finalmente, cada grupo expuso detalladamente los mapas realizados a todos los participantes y organizadores del taller. Entre las respuestas destacan dos grupos principales en la percepción de los ribereños: Elementos naturales y culturales del paisaje. Entre los elementos naturales destacan la dinámica de las aguas y el calor, entre los culturales las escaleras y la Iglesia. De todos los elementos citados, el calor obtuvo mayor destaque, tanto en los grupos de hombres como en los de mujeres en todas las comunidades trabajadas. Los mapas y las narrativas apuntan diferencias sutiles en las percepciones entre los grupos, los cuales, sienten mayores impactos negativos en los estiajes extremos. Los miembros comunitários perciben los cambios en relación a eventos fluviales y pluviales, y del aumento de la temperatura por medio del calor.

Palabras clave: Mapas mentales; Grupos focales; Percepción climática en la Amazonía; Comunidades de la Amazonía.

\section{Introdução}

O ambiente é pauta de urgência em nosso tempo. Sua constituição a partir de elementos naturais e artefatos humanos incide uma compreensão que resulta das interações do meio com os fenômenos da cultura e das vivências sociais. Dessa forma, sua percepção pode mudar de acordo com inúmeras variáveis como o próprio arranjo natural, além da concepção de tempo e de espaço que aparecem como indissociáveis à compreensão humana em seu modo de apropriação de determinado ambiente (Carlos, 2001; Silva, 2008).

Quando se verifica a percepção de uma população em torno da dinâmica da paisagem de determinado ambiente é necessário levar em consideração alguns elementos, como o risco e a adaptação. A Percepção Ambiental - PA do risco ocasiona a necessidade de se adaptar às mudanças, e segue, quase sempre, uma determinada sequência: 1. Percepção de acontecimentos de eventos extremos hidrológicos; 2. Percepção da dinâmica da paisagem cultural; 3. Percepção e identificação do risco; 4. Medidas de adaptação (Curi et al., 2016).

Desse modo, os estudos de PA em comunidades sobre dinâmicas de paisagem sociocultural em decorrência dos eventos extremos hidroclimáticos são importantes para a melhoria da qualidade de vida. Os dados advindos de tais estudos identificam os impactos causados pelos eventos e pela busca de adaptações, por parte de gestores públicos, adequadas a essas novas realidades. Uma das técnicas utilizadas no estudo da PA coletiva é a cartografia social, a qual está no bojo das pesquisas participativa e colaborativa, onde a reflexão, a organização e a ação em torno de um espaço físico e social específico são elementos que tecem a compreensão da realidade (Vélez Torre, Ganona \& Corredor, 2012).

A cartografia social é uma técnica que vai além do do mapeamento coletivo, como prática de apropriação de técnica simples de mapeamento, pois utiliza as experiências e representações prévias, seja de organizações e comunitários, como de quem impulsiona o trabalho (Iconoclasistas, 2011). A representação que as pessoas têm sobre sua territorialidade é um dos desafios do processo de sistematização, pois há a combinação dos exercícios de reflexão espacial-territorial com exercícios de reflexão temporal-coletiva (Andrade, 2001). Por fim, tais elementos são mesclados com memória e territorialidade construídas no dia a dia das comunidades. O território deve ser considerado em sua dinâmica completa histórica-geográfica.

Neste caminho, os mapas mentais surgem como ferramenta que contribuem na representação das percepções das 
comunidades do seu lugar frente aos eventos extremos hidroclimatológicos ocorridos na região do rio Negro, Amazonas. Os mapas mentais são "[...] representações mentais que cada indivíduo possui dos espaços que conhece. Este conhecimento é adquirido direta (através de percepções dos lugares que lhe é familiar, os espaços vividos) ou indiretamente através de leituras, passeios e informações de terceiros (revistas, livros, jornais, rádio etc.)” (Nogueira,1994, p.14).

A construção dos mapas mentais só se torna possível ao se utilizar a memória, principalmente, quando ela se torna um dos caminhos encontrados para buscar significados e percepções culturais às dinâmicas de paisagem sociocultural. A memória é a capacidade de formar uma consciência da identidade, tanto no nível pessoal como no coletivo, sendo por sua vez relacionada ao tempo (Assmann, 2008).

Assim, este artigo tem por finalidade verificar a percepção dos comunitários sobre as mudanças na dinâmica paisagística da Reserva de Desenvolvimento Sustentável - RDS Rio Negro provocada por eventos extremos hidroclimáticos. Tal finalidade se articula a partir da construção coletiva de mapas mentais como forma de representação de comunitários ribeirinhos acerca dos aspectos socioclimáticos vivenciados por eles.

\section{Metodologia}

As RDS emergem no Brasil como política pública que busca, fundamentalmente, constituir-se como uma unidade de conservação inserida no âmbito do Sistema Nacional de Unidades de Conservação com a intenção do uso sustentável e o manejo protegido em torno dessas áreas (Brasil, 2000). Em 2008, é criada a Reserva de Desenvolvimento Sustentável do rio Negro com o objetivo preservar a natureza e assegurar as condições necessárias às populações tradicionais em relação a qualidade de vida (Amazonas, 2008). Com efeito, a pesquisa foi realizada em quatro comunidades ribeirinhas da RDS rio Negro, Amazonas (Figura 1): Tiririca, Santo Antônio e Marajá no município de Novo Airão e Terra Preta em Iranduba.

Figura 1 - Localização das comunidades e da RDS do rio Negro, Amazonas.

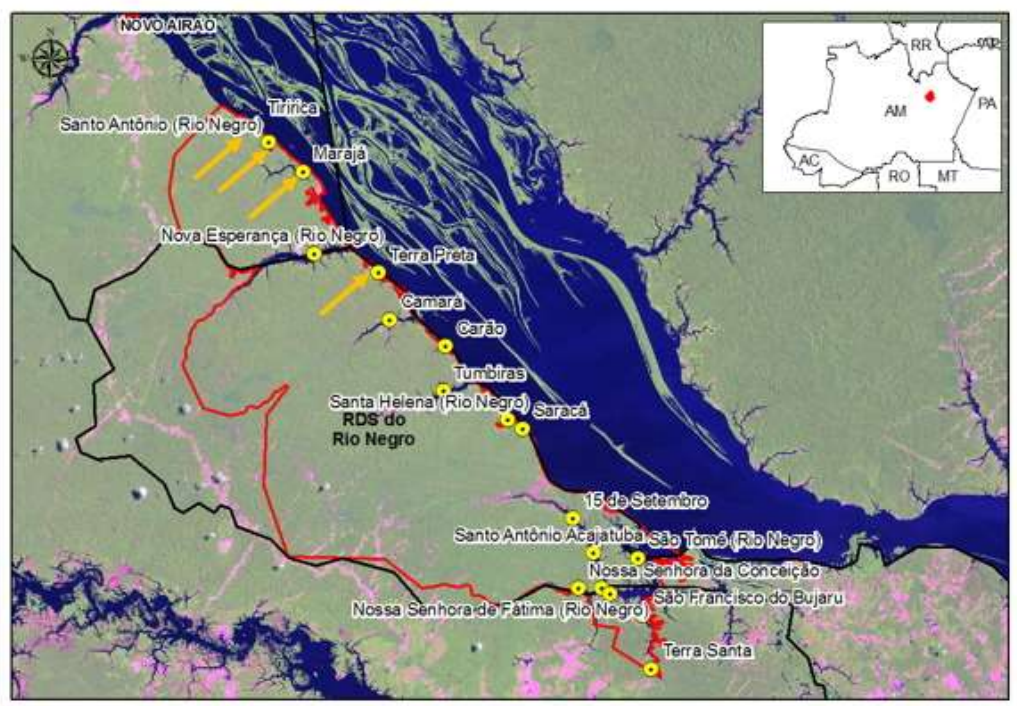

Fonte: elaborado pelos autores (2020).

A RDS rio Negro, dessa forma, é uma unidade de conservação de uso sustentável, criada a partir do desmembramento da Área de Proteção Ambiental da margem direita do rio Negro e está localizada na margem direita do rio Negro, abrangendo os municípios de Iranduba, Novo Airão e Manacapuru no Estado do Amazonas (Funbio, 2013). A paisagem da unidade é composta por florestas de terra firme, florestas alagadas e as matas de igapó. O clima quente e úmido definido como equatorial 
é predominantemente condicionado pelos processos hidroclimatológicos da floresta trópico-equatorial úmida (Salati et al., 1978). A temperatura varia em torno dos $28^{\circ}$, e a precipitação entre 2.200 a 2.400mm (Amazonas, 2002).

A população residente na RDS rio Negro está distribuída em 19 comunidades, a maioria formada nas décadas de 1980 e 1990. A maior delas é a comunidade Nossa Senhora do Perpétuo Socorro, com 104 residências, e a menor é a comunidade de Santo Antônio, com 13 residências (Sema, 2016). As comunidades foram selecionadas a partir de critérios pré-estabelecidos que são: comunidades com acesso somente por via fluvial; maiores núcleos populacionais; comunidades mais antigas por possuírem moradores com maior tempo de moradia; comunidades mais próximas às margens do rio.

Os sujeitos da pesquisa são os moradores das comunidades ribeirinhas de Terra Preta, Santo Antônio, Marajá e Tiririca, homens e mulheres maiores de 18 anos de idade. Participaram desse estudo 50 comunitários divididos entre as quatro comunidades supracitadas. Do total, 36\% $(n=18)$ da comunidade Marajá, 32\% ( $n=16)$ em Tiririca, $16 \%(n=8)$ em Terra Preta e 16\% ( $\mathrm{n}=8)$ em Santo Antônio. Dos participantes, 58\% foram representados por homens e $42 \%$ mulheres. O projeto foi apresentado previamente a todas as comunidades selecionadas e todos os participantes assinaram o Termo de Consentimento e Livre Esclarecimento - TCLE com CAAE 88672418.7.0000.5020 e parecer 2.872.385 em setembro de 2018.

A seleção dos sujeitos da pesquisa nas comunidades estudadas ocorreu por meio de cadeias de referências de amostragem de Bola de Neve (Biernacki \& Waldorf, 1981). Neste sentido, a indicação inicial partiu do gestor da RDS rio Negro que apontou as principais lideranças das comunidades estudadas e a coleta de dados primários foi iniciada em agosto de 2018.

O estudo apresentado é de natureza qualitativa uma vez que oportuniza a interação dos elementos simbólicos do fenômeno observado (Denzin; Lincoln, 2006). O estudo, ainda, revestiu-se de um processo de coleta de elementos empíricos e exploratório (Minayo, 2011). As coletas de dados primários foram realizadas por intermédio de mapas mentais e grupos focais. Durante a aplicação utilizamos diários de campo e registros fotográficos. Esta atividade contou com a participação de um moderador que facilitava a interação dos grupos e de um observador que tinha a função de captar as informações verbais e não verbais. Ao término, ambos avaliaram a atividade para detectar possíveis vieses ocasionados por problemas decorrentes na aplicação deste (Westphal, Bógus \& Faria, 1996).

Para a operacionalização, em cada oficina, os comunitários foram divididos em dois grupos, organizados a partir do gênero, isto é, um composto por homens e outro por mulheres. Ambos os grupos receberam cartolina, lápis e pinceis e foram orientados a elaborar o mapa mental da comunidade que ilustrassem dois momentos: uma grande cheia e uma grande seca do rio Negro, observando a diferença de percepção entre os gêneros diante dos eventos extremos.

Cada grupo expôs o detalhamento dos mapas elaborados a todos os participantes e organizadores. O moderador utilizou um roteiro que foi preenchido pelo observador e conforme necessário fazia a intervenção junto aos participantes para que ficassem claras as etapas. Na medida em que apresentavam os mapas, os comunitários eram questionados sobre suas percepções climáticas, atividades impactadas com os extremos e as possíveis adaptações realizadas com as atuais e futuras mudanças devido aos eventos extremos. Os dados do roteiro possibilitaram a criação de um quadro com as respostas dos participantes para a realização da análise dos resultados a partir da interpretação e da fala dos próprios comunitários, buscando ao máximo evitar interferência dos moderadores. Dessa forma, a partir de uma análise descritiva esboçam-se, a seguir, os referidos resultados.

\section{Resultados e Discussão}

Como política do estado brasileiro, a RDS emerge como importante estratégia de proteção ambiental de áreas do território nacional. Sua finalidade básica de preservação e conservação do ambiente natural é considerada relevante e acentua um caminho construído para lidar com as urgências ambientais vivenciadas no Brasil nos últimos anos, principalmente, em 
relação ao desmatamento, as queimadas e o avanço do agronegócio.

Nesse sentido, como uma das principais ações da política em torno do meio ambiente no Brasil e uma das mais antigas e efetivas no mundo (Martins, 2012), a escuta dos moradores da RDS rio Negro sinaliza para a relevância essa perspectiva, destacando que a proteção da natureza está inserida na percepção dos moradores, evidenciada nas seguintes respostas:

"A natureza ficou mais protegida" (Comunitário, Terra Preta 20, sexo masculino).

"Com a RDS melhorou. A floresta fica guardada para as gerações futuras" (Comunitário, Tiririca 7, sexo masculino).

Observa-se nas "vozes" dos comunitários que os fundamentos que sustentam as políticas ambientais, no âmbito da RDS, estão impregnados das concepções advindas dos discursos de mobilização ambientalista, tanto civil quanto acadêmico, as quais se aglutinam em torno de uma orientação voltada ao desenvolvimento sustentável. Essa perspectiva visa articular a conservação da natureza com o manejo sustentável dos recursos, de tal modo que a RDS pode ser "resguardada para as gerações futuras".

Em outras palavras, ações menos intervencionistas do ser humano junto ao ambiente no qual estão inseridos tem por finalidade preservar e garantir uma manutenção natural, a qual tem por finalidade evidenciar que os recursos ambientais possuem uma limitação e estão na base da viabilização socioeconômica (Marconatto et al., 2013).

É nessa conjuntura que se observa nas narrativas dos moradores sinalizações em torno de algumas práticas. Eles destacam que com a criação da RDS do Rio Negro há uma redução no desmatamento, nas queimadas, na caça e na pesca, por exemplo:

"Antes tinha mais desmatamento, caça e tudo podia. Agora só fazem roçado em área aberta" (Comunitário, Marajá 7, sexo feminino).

"Ajudou na redução das queimadas e do desmatamento" (Comunitário, Tiririca 3, sexo feminino).

"Melhorou, reduziu o desmatamento e a pesca ilegal" (Comunitário, Terra Preta 10, sexo masculino).

Outro elemento importante nesse contexto é que a RDS evoca um senso de comunidade e pertencimento nos moradores. Nota-se essa condição quando se destaca que "[...] as pessoas passaram a morar mais juntas (Comunitário, Santo Antônio 2, sexo masculino), onde essa proximidade reverbera-se em um instrumento de vigilância e fiscalização em torno dos bens naturais, impedindo e monitorando, por vezes, a invasão de outros moradores na RDS, a retirada ilegal de madeira e a caça de animais.

Esse destaque em relação à proteção aos recursos naturais emerge de forma saliente nas narrativas dos moradores. Por outro lado, os comunitários apontam para singulares transformações paisagísticas e climáticas na RDS rio Negro, principalmente associadas a conexão com o rio, a qual impõe uma dualidade paisagística, ora um tempo e espaço de cheia ora um tempo e espaço de seca, que acaba por regular relações sociais e econômicas das comunidades ribeirinhas.

A dinâmica do rio e suas sazonalidades constituem como agente transformador da paisagem e do modus de vida da região (Tocantins, 2000). A relação com sazonalidade dos rios interfere na tessitura social, como a periodicidade escolar, onde a assiduidade de crianças no ambiente escolar em comunidades ribeirinhas é menor no período de vazante e seca dos rios (Pereira, et al., 2018). Essa situação ocorre, fundamentalmente, devido as enormes distâncias que os alunos devem percorrer entre suas residências até as margens dos rios para ter acesso a um transporte fluvial até a escola, além de maior risco de ataques de animais, como cobras. 
A trajetória das águas dos rios impacta, assim, a construção da percepção dos moradores da RDS rio Negro e é resultante dos eventos extremos fluviais que ocorrem com maior frequência na região nas últimas décadas. Essa mudança no padrão sazonal dos rios e seus consequentes extremos hidroclimatológicos deve-se a mudança climática global (Marengo, 2008).

Inserido nesse contexto, é possível identificar alguns elementos na dinâmica socioambiental da RDS rio Negro, onde os moradores conseguem perceber as modificações ocasionadas na paisagem, tanto natural quanto cultural, da reserva diante das vivências desses extremos hidroclimatológicos. Destaca-se que a complexidade que perpassa nosso contexto (Morin, 2005; 2007) ancora na compreensão da realidade a partir da articulação entre ser humano e ambiente. De outro modo, Morin (2015, p. 112) afirma: "como todo o conhecimento, o conhecimento da natureza situa-se num contexto e enraizamento cultural, social e histórico". Dessa forma, a noção de paisagem utilizada nesse texto considera tantos os elementos socioculturais quanto o natural em consonância aos seus mapas mentais e as suas "vozes" expressas nos grupos focais nos quais temos as percepções nos próximos tópicos.

\subsection{Elementos naturais da paisagem}

\subsubsection{A dinâmica das águas}

A primeira percepção dos comunitários em torno das mudanças ocorridas na dinâmica paisagística RDS rio Negro está vinculada ao rio. Na tradição indígena amazônica algumas tribos apontam a água como elemento primordial para e emergência da vida. Na visão nheengatu, por exemplo, no início da criação do mundo havia só água e tudo era vazio. Dessa condição, Tupana, criador de tudo, começa a dar forma aos seres. Por sua vez, a cosmovisão da cultura caboclo-ribeirinha está impregnada da dinâmica das águas, principalmente, dos rios. "Os rios na Amazônia constituem uma realidade labiríntica e assumem uma importância fisiográfica humana excepcional. O rio é fator dominante na estrutura fisiográfica e humana, conferindo um ethos e um ritmo à vida regional" (Fraxe, 2004, p.330).

Desse modo, na cheia para as comunitárias de Marajá a maior referência é o próprio rio, pois o acesso da comunidade se dá pelo igarapé Marajá como observado nas Figuras 2A e 2B. Embora a cheia seja menos produtiva, a água do rio fica menos quente e isso é citado como algo positivo. Nesse período a paisagem é mais verde por causa das árvores, e ter mais água facilita o deslocamento das crianças e adolescentes para a escola, localizada na comunidade Santo Antônio. Uma observação citada pelas participantes foi em relação à mudança na dinâmica da sazonalidade: "[...] o rio está subindo e descendo mais rápido".

Figura 2 - A) Foto (seca) e B) mapa mental (cheia) da comunidade Marajá (mulheres).
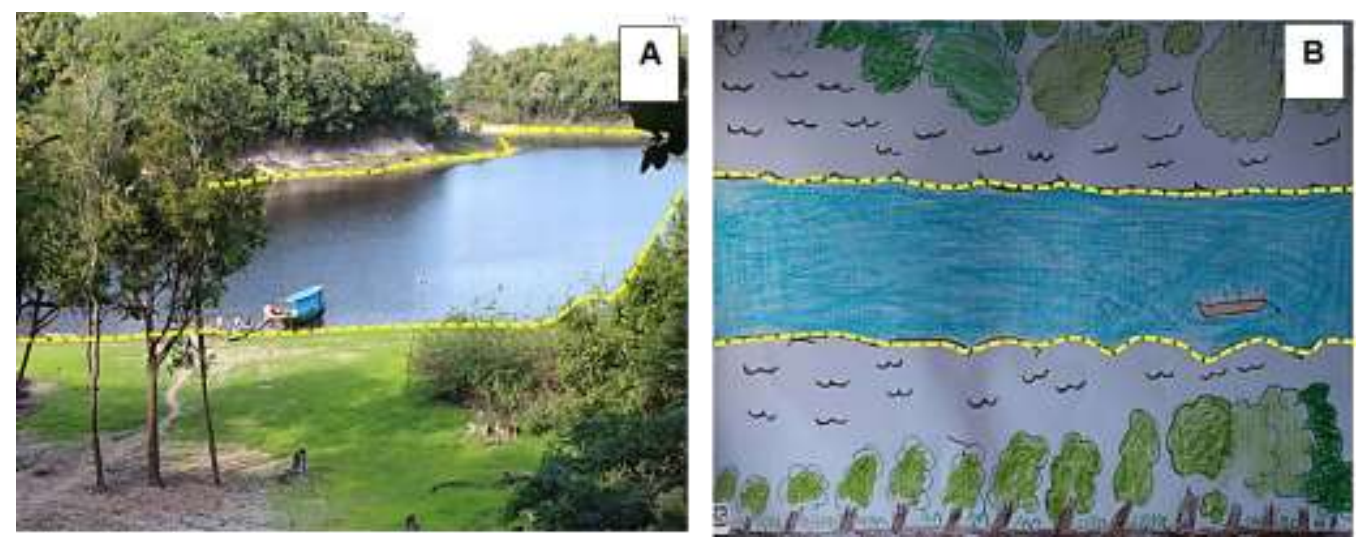

Fonte: trabalho de campo, novembro de 2018. 
Outro elemento natural em que se observa alguma mudança na paisagem da RDS rio Negro, também associada à dinâmica das águas é o ciclo da chuva. Presente principalmente, nas narrativas das comunitárias que acreditam na mudança do calendário regular das chuvas e isso colabora na ocorrência de incêndios na mata.

Em Terra Preta as mulheres percebem as grandes secas como uma dificuldade na realização dos trabalhos na pesca, na agricultura e na extração da madeira. Nas grandes secas há mais peixes, no entanto, a dificuldade de acesso traz a necessidade de utilização de canoas menores. As grandes secas estão associadas a períodos de menor precipitação e maior quentura, segundo as comunitárias:

"Está chovendo mais nos últimos tempos, mas não chove desde agosto" (mulheres de Terra Preta. Trabalho de campo em novembro de 2018).

"Nas cheias as folhas úmidas da floresta evitam os incêndios" (mulheres de Terra Preta. Trabalho de campo em novembro de 2018).

As falas em destaque apontam que as mulheres percebem uma maior intensidade das chuvas na região, entretanto, com estações secas prolongadas. Elas relacionam a umidade da floresta à proteção contra incêndios, assim como os estudos científicos de Nobre (2014) que apontam que as correntes de ar carregam umidade da bacia Amazônica para o Centro-Oeste, Sudeste e Sul do Brasil. A construção perceptual em torno da dinâmica das águas está majoritariamente vinculada as falas das mulheres. Os rios emergem como fonte e origem da vida. São os rios que potencializam a dinâmica da vida na RDS e as mulheres, reconhecem tais sentidos no seu cotidiano.

\subsubsection{A quentura}

Outro elemento natural em que se nota interferência na paisagem da RDS é a nominada quentura. A quentura pode ser dita como o próprio calor, sendo descrita por Valente (2011) por acompanhar o afixo "ura" de caráter ardente como quente em excesso. A quentura está intensa desde os anos 2000 e pode ter relação com as queimadas na região, prejudicando o trabalho na pesca e na agricultura. Para Souza et al. (2020), nas próximas décadas as atividades laborais à céu aberto, como é o caso da agricultura e pesca, terão uma drástica redução devido ao aumento de doenças geradas a essas classes de trabalhadores por estarem expostos ao calor intenso.

Com efeito, se a dinâmica das águas é fator de percepção que predomina entre as mulheres, a quentura, por sua vez, está vinculada aos homens. Os homens de Santo Antônio relacionaram as grandes secas a maior ocorrência de quentura, mormaço e queimadas na comunidade. Nas secas há mais peixes nos lagos e tracajás nas praias formadas no período, por outro lado a seca e a quentura atrapalham o trabalho da pesca e da agricultura pelo incômodo causado pelo calor e, ainda, podem levar a morte do plantio. Além disso, ocorrem mais temporais e o banzeiro (agitação que forma ondas) do rio fica mais forte. Os comunitários não destacaram fatos relacionados às grandes cheias do rio Negro. Na comunidade Marajá, os homens evidenciaram a categoria de quentura como a maior influenciadora na paisagem sociocultural, pois afeta a pesca, agricultura, a temperatura da água do rio, o banzeiro mais forte e a maior ocorrência e intensidade de temporais, sendo estes acompanhados de mais raios. Os comunitários acreditam que as estações mudaram:

"O inverno começava em novembro (chuvas), mas agora só ameaça temporal e não chove" (Homens da comunidade Marajá. Trabalho de campo, 2018).

Para os homens de Tiririca, antigamente, as cheias eram menores: "[...] a última grande ocorreu em 1953, mas depois de 2000 aconteceram 3 eventos grandes”. A grande cheia é um período difícil para a pesca, mas facilita a caça e o transporte da 
madeira cerrada. Nas grandes cheias aparecem casos de pessoas com malária na comunidade. Já nas grandes secas há maior disponibilidade de peixes, mas fica difícil tirar e transportar madeira. A seca e a quentura juntas dificultam a pesca e a agricultura e os homens percebem mudanças no meio ambiente "[...] Está tudo mudado, houve mudança climática" (Homens da comunidade Marajá. Trabalho de campo, 2018).

Nas grandes secas na comunidade Terra Preta, os homens sentem maiores dificuldades de trabalho, visto que geralmente esses eventos vêm acompanhado de quentura excessiva. A agricultura, a pesca e a extração madeireira são afetadas negativamente, além da ausência de água potável que ocasiona diarreia e a dificuldade de acesso ao tratamento médico, pelo isolamento das comunidades com as águas em níveis baixos. A principal problemática nas grandes cheias foi o alagamento de casas da comunidade em 2009 e 2012 e a menor disponibilidade de peixes, mas as cheias são vistas como benéficas, mesmo quando ultrapassam as cotas normais. Na percepção dos comunitários em relação à sazonalidade do rio Negro:

"Na cheia tudo fica mais fácil, chove mais do que na seca e tem menos calor" (Homens da comunidade Marajá. Trabalho de campo, 2018).

"As cheias e secas estão diferentes desde 2006, mudou o periodo de descer e subir e a cota do rio mudou" (Homens da comunidade Marajá. Trabalho de campo, 2018).

Em estudo de percepção ambiental com agricultores, Gomes e Martins, (2020) concluíram que metade dos entrevistados não realizavam práticas ambientais sustentáveis em relação as nascentes devido ao desconhecimento sobre a importância destas. Os autores apontam a importância da educação ambiental na mudança positiva da realidade dos produtores, ou seja, perceber o ambiente ao qual estão inseridos é ferramenta fundamental.

Evaristo et al., 2016 em estudo de percepção ambiental na comunidade rural de Candidópolis em Itabira, Minas Gerais apesar de encontrarem condições precárias de saneamento as quais causam impactos negativos, concluíram que há uma falta de percepção ambiental dos moradores em relação à problemática que os circunda.

\subsection{Elementos culturais da paisagem}

A verificação dos elementos culturais não perpassa a ideia de um sistema estático, mas dinâmico. Sua dinamicidade acontece tanto internamente, através de seus membros, como externamente através do contato com outros grupos. Nesse sentido, é possível identificar alguns elementos que colaboram para esse entendimento, como a escada e a igreja.

\subsubsection{A escada}

Nas comunidades amazônicas a construção da escada é elemento fundamental. As constantes erosões nas beiras dos rios, a irregularidade dos terrenos e a necessidade de acessar o rio seja para escoar alimentos ou deslocar-se para outras comunidades, por exemplo, destacam a escada na paisagem amazônica. É a ligação direta entre o rio e a vida da comunidade. É por ela que a vida pessoal e social transcorre na comunidade.

As mulheres de Santo Antônio tiveram como referência espacial a escada na entrada da comunidade para os eventos de grande seca e cheia como observamos nas Figuras 3A e 3B. A escada tem grande utilidade em eventos de secas extremas devido à localização da comunidade no alto, no entanto, em grandes cheias ela não possui muita serventia, uma vez que os barcos e canoas ficam bem próximos da entrada e das casas. 
Figura 3 - Mapa mental da Comunidade Santo Antônio: A) seca e B) cheia (mulheres).
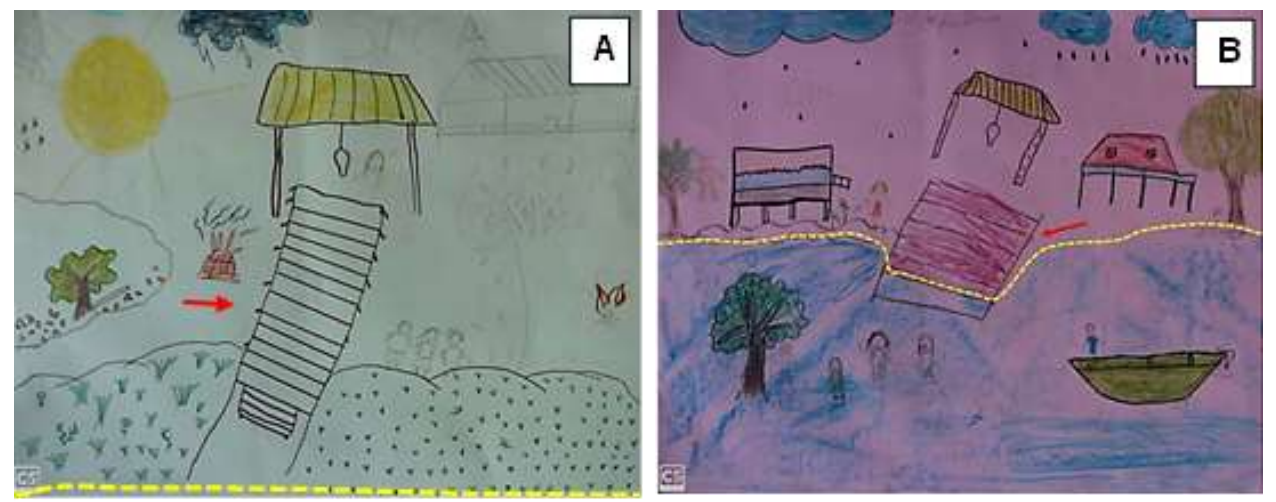

Fonte: trabalho de campo, novembro de 2018.

As secas normais ou extremas são marcadas por enorme quentura que somada à falta de energia elétrica dificulta bastante o trabalho dos comunitários "[...] não tem quem beba a água do rio", tendo o sol como destaque no mapa e nas falas, são acompanhadas por temporais mais frequentes e intensos, causam a morte das plantas e é o período no qual são realizadas algumas queimadas. Contudo, as secas facilitam o trabalho com a madeira (derrubada e serragem). As grandes cheias têm relação com as chuvas como citada pelas mulheres “[...] a cheia é o período que mais chove”, modificam a paisagem física com a escada sendo coberta pela água, são consideradas boas para o plantio, para o transporte da madeira serrada nas secas e é citada como um bom momento para o lazer, já que elas ficam mais tempo dentro do rio.

$\mathrm{Na}$ percepção dos indígenas Wapichana que ocupam tradicionalmente os vales do rio Uraricoera e do rio Tacutu no estado de Roraima, as mudanças climáticas estão ocorrendo e o aquecimento das águas dos rios fez vários peixes regionais migrarem para outros lugares (Alcantara, 2019). Populações indígenas, ribeirinhas das áreas rurais são os primeiros a perceberem os efeitos dos desequilíbrios ecossistêmicos causados pela mudança de temperatura do planeta (Ecodebate, 2019).

As mulheres de Marajá também evidenciaram a escada na frente da comunidade como observado na Figura 4. As comunitárias apontaram como maior problema em grandes secas a quentura junto à falta de chuvas, o que traz risco de incêndios na comunidade, como destacado no mapa elaborado. Os incêndios florestais são comuns no verão amazônico, ocasionados pela falta de precipitação, redução da umidade e aumento da temperatura. Entretanto, existe um aumento na quantidade desses fenômenos nos últimos anos. No ano de 2020 o estado do Amazonas obteve a maior quantidade de focos de calor desde 1998, totalizando 16.729, com destaque para os meses de julho e agosto que possuem a maior quantidade de registros da série histórica (Inpe, 2021).

Figura 4 - Comunidade Marajá, seca (mulheres).

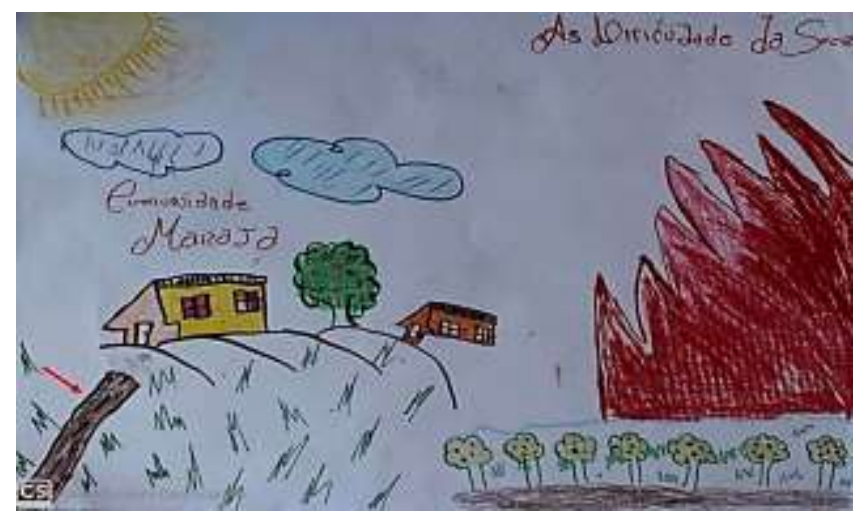

Fonte: trabalho de campo, novembro de 2018. 


\subsubsection{A igreja}

Pierre Bourdieu (1989) destaca que o ser humano faz parte de um sistema simbólico, onde mitos, crenças, dogmas e ritos constroem e ordenam uma forma de conceber o mundo, que difere daquilo que preconiza a ciência ou técnica moderna. A religiosidade, enquanto uma das configurações dos sistemas simbólicos, estabelece uma continua relação do ser humano com uma dimensão transcendental. Mircea Eliade (1992) destaca que essas relações se manifestam entre o mundo profano e o mundo sagrado, os quais são eixos fundamentais para o entendimento da existência.

Assim como os demais construtos sociais, o discurso religioso conduz uma forma e uma maneira de conceber a existência e aquilo que está além dela, legitimando-a como um modo específico de ligar a individualidade de cada um à coletividade social. É nesse sentido, que a referência física da comunidade Tiririca é a igreja localizada no alto das pedras nas proximidades com as árvores, como ilustrada nas Figuras 5A e 5B. A grande cheia de 2012 destruiu a igreja que precisou ser reconstruída.

Figura 5 - Mapas mentais da comunidade Tiririca: A) seca e B) cheia (mulheres).
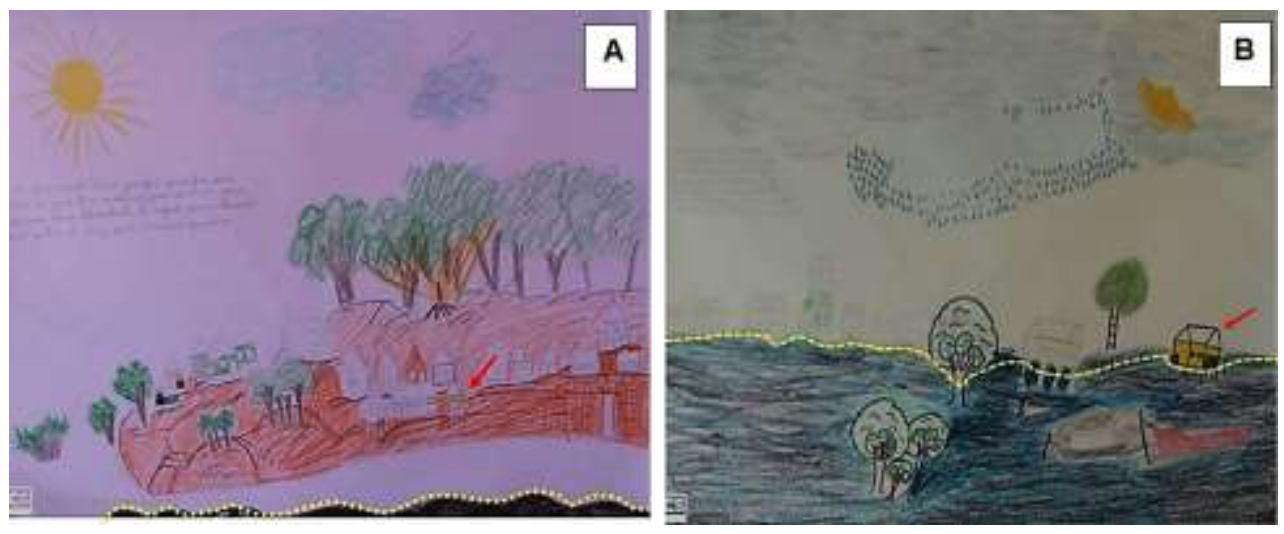

Fonte: trabalho de campo, novembro de 2018.

Tiririca é uma das menores comunidades da RDS do rio Negro e possui muitos moradores idosos que sentem os impactos das secas severas por dificultar o acesso a água e ao banho de rio, visto que não há energia elétrica na comunidade que possa auxiliar no abastecimento das residências. Além disso, a alteração climática gera insegurança para a população mais idosa, pois na ocorrência de eventos extremos podem ocorrer acidentes e traumas que podem deixar mais vulnerabilizada essa população, além disso, os idosos são os mais suscetíveis a uma série de doenças infecciosas que podem ser propagadas devido a alteração climática (Nogueira et al., 2011).

A vida cultural, o pertencimento a uma comunidade ribeirinha e o envolvimento com os aspectos sociais que a constituem são influenciadas pelo aspecto da religiosidade. A ida ao culto dominical, seja católico ou evangélico, mobiliza a comunidade integrando e constituindo a identidade e a cultura do caboclo ribeirinho. Dentro dessa perspectiva, as crenças doutrinas de determinadas tradições religiosas misturam-se às crenças em poderes sobrenaturais e às práticas mágicas de origem nativa que evidencia uma identidade e uma cosmovisão acerca do mundo.

\section{Considerações Finais}

A percepção dos participantes aponta as categorias de grandes cheias e secas do rio Negro somadas às categorias de chuva e quentura na região como elementos que modificam a paisagem sociocultural. Os mapas e as narrativas desvelam diferenças pequenas nas percepções entre os grupos, em especial nas referências físicas paisagísticas de cada comunidade. É notório que as comunidades sentem maiores impactos negativos com as secas extremas. 
Os comunitários percebem as mudanças em relação às chuvas, o aumento da temperatura por meio da quentura e um aumento das ocorrências de eventos extremos de cheias e secas no rio Negro, sendo o seu conhecimento tradicional fundamental nessa conceituação do ambiente. E ainda, as características ambientais de localização e altitude, influenciam na percepção dos comunitários em relação aos impactos dos eventos extremos hidroclimatológicos. A categoria de maior queixa de aumento pelos comunitários foi a quentura e tem relação direta com o desmatamento, a queimada e poluição ambiental.

Realizar um estudo perceptual possibilita a compreensão das interfaces que atravessam a relação pessoa-ambiente, uma vez que oportuniza reconhecer como os sujeitos interagem com o ambiente ao passo que é possível observar e verificar as influências do ambiente sobre os sujeitos. Assim, espera-se que o estudo possibilite uma problematização em torno da incidência dos eventos extremos na Amazônica, bem como possa incentivar novas pesquisas na região do rio Negro, oportunizando assim um espectro teórico-empírico que fundamente o surgimento de políticas públicas voltadas à essa temática na região.

\section{Agradecimentos}

O presente trabalho foi realizado com apoio da Coordenação de Aperfeiçoamento de Pessoal de Nível Superior Brasil (CAPES) - Código de Financiamento 001.

\section{Referências}

Amazonas. (2002). Documento preliminar sobre a Área de Proteção Ambiental da Margem Direita do Rio Negro Setor Paduari-Solimões. Manaus: IPAAM.

Amazonas. (2008). Lei $n .^{\circ} 3355$, de 30 de dezembro de 2008. Dispõe sobre a criação da Reserva de Desenvolvimento Sustentável do Rio Negro. Assembleia Legislativa do Estado do Amazonas. https://sapl.al.am.leg.br/media/sapl/public/normajuridica/2008/7810/7810_texto_integral.pdf\#: :text $=0 \% 20$ Poder $\% 20$ Executivo $\% 20 \mathrm{e} \% 20 \mathrm{a}$,Art.

Andrade, H. (2001). La cartografía social para la planeación participativa: experiencias de planeación con grupos étnicos en Colombia. Caracas: Centro Latinoamericano de Administración para el Desarrollo. http://uvirtual.unet.edu.ve/mod/resource/view.php?id=45146.

Assmann, J. Comunicative and cultural memory. In: Erll, A.; Nunning, A. (Ed.). (2008). Cultural memory studies: an international and interdisciplinar, handbook. Berlin; New York: De Gruyter. p. $109 \quad$ - $118 . \quad$ Tradução: Méri http://revista.historiaoral.org.br/index.php?journal=rho\&page=article\&op=view\&pa th\%5B $\% 5 \mathrm{D}=642 \&$ path $\% 5 \mathrm{~B} \% 5 \mathrm{D}=\mathrm{pdf}$.

Baldin, N., \& Munhoz, E. M. B. (2011). Educação ambiental comunitária: uma experiência com a técnica de pesquisa snowball (bola de neve). Revista eletrônica do Mestrado em Educação Ambiental, 27: 46-60. https://periodicos.furg.br/remea/article/view/3193/1855.

Biernacki, P., \& Waldorf, D. (1981). Snowball Sampling: Problems and techniques of Chain Referral Sampling. Sociological Methods \& Research, vol. N. ${ }^{\circ}$, November. p. 141-163. https://journals.sagepub.com/doi/10.1177/004912418101000205.

Bourdieu, P. (1989). O Poder Simbólico. Tradução de Fernando Tomaz. Rio de janeiro: Bertrand Brasil.

Brasil. (2000). Lei n. ${ }^{\circ}$ 9.985, de 18 de julho de 2000. Institui o Sistema Nacional de Unidades de Conservação da Natureza e dá outras providências. Presidência da República. http://www.planalto.gov.br/ccivil_03/leis/19985.htm.

Carlos, A. F. A. (2001). Espaço-tempo na metrópole: fragmentação da vida cotidiana: Contexto.

Curi, M. V., Litre, G., Ibiapina, I., \& Andrade, A. J. P. (2016). Mudanças Climáticas e Percepção Ambiental: Contribuições da Antropologia do Clima. In: Bursztyn M, Rodrigues Filho S (Org.). O Clima em Transe: vulnerabilidade e adaptação da agricultura familiar, Garamond, Rio de Janeiro, p. $35-52$.

Denzin, N. K., \& Lincoln, Y. S. (2006). O Planejamento da pesquisa qualitativa: teorias e abordagens: Artmed.

Eliade, M. (1992). O Sagrado e o Profano. Tradução Rogério Fernandes: Martins Fontes.

Evaristo, G. V., Cordeiro, J., Alvarenga, C. A., Oporto, L. T., Quintão, P. L., Calazans, G. M., \& Cordeiro, J. L. (2016). Basic sanitation and environmental perception: a study in Candidópolis community in Itabira, Minas Gerais. Research, Society and Development, [S. l.], 4(1), 45-61. 10.17648/rsd-v4i1.28.

Fraxe. T. J. P. (2004). Cultura Cabocla-Ribeirinha: mitos, lendas e transculturalidade. (2a .ed.): Annablume.

Funbio. (2013). Reserva de Desenvolvimento Sustentável do Rio Negro. http://www.funbio.org.br/wp-content/uploads/2014/03/TdR2013.0527.00015-6-RDSRio-Negro-1.pdf

Gomes, K. B. P., \& Martins, R. C. C. (2020). Education and sustainability in the rural environment: a case study on the perception of family farmers. Research, Society and Development, 9(7): 1-26, e507974429. 
Iconoclasistas. (2011). Reflexiones cartográficas II. http://iconoclasistas.com.ar/2011/05/19/reflexiones-cartograficas-ii/.

Inpe. (2021). Monitoramento dos Focos Ativos por Estado: Comparação do total de focos ativos detectados pelo satélite de referência em cada mês, no período de 1998 até 03/05/2021. https:/queimadas.dgi.inpe.br/queimadas/portal-static/estatisticas_estados/.

Maconatto, D. A. B., et al. (2013). Saindo da trincheira do desenvolvimento sustentável: uma nova perspectiva para a análise e a decisão em sustentabilidade. Revista de Administração Mackenzie, São Paulo, 14(1), Janeiro/Fevereiro.

Marengo J. A., Nobre C. A., Tomasella J., Cardoso M. F., \& Oyama M. D. (2008). Hydro-Climatic and Ecological Behaviour of the Drought of Amazonia in 2005. Philosophical Transactions of The Royal Society, 363:1773-1778.

Martins, A. (2012). Conflitos ambientais em unidades de conservação: dilemas da gestão territorial no Brasil. Revista Bibliográfica de Geografía y Ciencias Sociales, Barcelona, 17(989), 1-11.

Minayo, M. C. S. (2011). Pesquisa social: Teoria, método e criatividade: Vozes.

Morin, E. (2005). Ciência com Consciência. ( $8^{\mathrm{a}}$ ed.): Bertrand Brasil.

Morin, E. (2007). Os Sete Saberes Necessários à Educação do Futuro. (12ª ed.): Cortez; Brasília: UNESCO.

Morin, E. (2015). O método II: a vida da vida. (5 ed.): Sulina.

Nobre, A. D. (2014). O futuro climático da Amazônia: relatório de avaliação científica. São José dos Campos, SP: ARA: CCST-INPE: INPA.

Nogueira, A. R. B. (1994). Mapa Mental: recurso didático no ensino de geografia no $1^{o}$ grau. Dissertação de Mestrado. DEGEO-USP. São Paulo. 208p.

Nogueira, V., Nogueira, R., Cândido, G., Souza, V., \& Silva, S. (2012). Efeitos das alterações climáticas e antrópicas na saúde do idoso. Revista Brasileira de Ciências do Envelhecimento Humano, 8(1), 6 ago

Pereira, H. S., \& Silva, S. C. P. da. (2018). Os impactos dos eventos hidrológicos extremos e a governança ambiental: estudo sobre a assiduidade dos alunos no distrito de Terra Nova, Careiro da Várzea/Am. Revista Terceira Margem Amazônia, 2(9).

Salati, E., Marques, J., \& Molion, L. C. B. (1978). Origem e distribuição das chuvas na Amazônia. Interciência, 3 (4): $200-206$

Secretaria de Estado de Meio Ambiente do Amazonas (SEMA). (2016). Plano de gestão da Reserva de Desenvolvimento Sustentável do Rio Negro. 348 p.

Silva, G. T. (2008). Percepções sócio-espaciais e de turismo em Paricatuba-Iranduba-Amazonas. Dissertação (Mestrado em Ciências do Ambiente e Sustentabilidade na Amazônia) — Universidade Federal do Amazonas. https://docplayer.com.br/16973865-Percepcoes-socio-espaciaise-de-turismo-emparicatuba-iranduba-amazonas-glaubecia-teixeira-da-silva.html.

Santos, B. S. (1991). Uma cartografia simbólica das representações sociais: prolegômenos a uma concepção pós-moderna do direito. Espaço \& Debates: Revista de Estudos Regionais e Urbanos, São Paulo, ano 11, n.33, p.63-79.

Souza, P. M. B., Corrêa, M. P., Torres, R. R., \& Silva, L. F. (2020). Influência das mudanças climáticas sobre as condições de trabalho no final do século XXI. Ambiente \& Sociedade. V. 23.

Souza, P. M. B., et al. (2020). Influências das mudanças climáticas sobre as condições de trabalho no final do século XXI. Ambiente \& Sociedade, São Paulo. 23, p.1-20. 2020;23: e00113.

Tocantins, L. (2000). O rio comanda a vida: uma interpretação da Amazônia. (9. a edição): Editora Valer/Edições Governo do Estado.

Valente, A. C. M. M. (2011). Nominalização em português: uma análise morfossemântica do afixo -ura. Palimpsesto. Revista do Programa de PósGraduação em Letras da UERJ, 10(13), 1-17, jun. 2011. ISSN 1809-3507. https://www.epublicacoes.uerj.br/index.php/palimpsesto/article/view/35362/25006.

Vélez Torre, I., Ganona, S. R., \& Corredor, D. V. (2012). Cartografía social como metodología participativa y colaborativa de investigación en el territorio afrodescendiente de la cuenca alta del río Cauca. Cuad. geogr. rev. colomb. geogr. 21(2), 59 - 73. ISSN electrónico 2256-5442. ISSN impreso 0121-215X. https://revistas.unal.edu.co/index.php/rcg/article/view/25774/36770.

Westphal, M. F., Bógus, C. M., \& Faria, M. M. (1996). Grupos focais: experiências precursoras em programas educativos em saúde no Brasil. Bol. Oficina Sanit. Panam. 120(6), 472-81. http://hist.library.paho.org/Spanish/BOL/v120n6p472.pdf. 